\title{
Partitioning uncertainty in projections of Arctic sea ice
}

\section{Journal Article}

\section{Author(s):}

Bonan, David B.; Lehner, Flavio; Holland, Marika M.

Publication date:

2021-04

Permanent link:

https://doi.org/10.3929/ethz-b-000478018

\section{Rights / license:}

Creative Commons Attribution 4.0 International

\section{Originally published in:}

Environmental Research Letters 16(4), https://doi.org/10.1088/1748-9326/abe0ec 


\section{ENVIRONMENTAL RESEARCH LETTERS}

\section{LETTER • OPEN ACCESS}

Partitioning uncertainty in projections of Arctic sea ice

To cite this article: David B Bonan et al 2021 Environ. Res. Lett. 16044002

View the article online for updates and enhancements. 


\title{
ENVIRONMENTAL RESEARCH
}

\section{LETTERS}

\section{LETTER}

CrossMark

OPEN ACCESS

RECEIVED

30 September 2020

REVISED

22 January 2021

ACCEPTED FOR PUBLICATION

28 January 2021

PUBLISHED

10 March 2021

Original Content from

this work may be used

under the terms of the

Creative Commons

Attribution 4.0 licence.

Any further distribution

of this work must

maintain attribution to

the author(s) and the title

of the work, journal

citation and DOI.

\section{Partitioning uncertainty in projections of Arctic sea ice}

\author{
David B Bonan ${ }^{1}$ (D), Flavio Lehner ${ }^{2,3,4}$ (iD) and Marika M Holland ${ }^{3}$ (D) \\ 1 Environmental Science and Engineering, California Institute of Technology, Pasadena, CA, United States of America \\ 2 Department of Earth and Atmospheric Sciences, Cornell University, Ithaca, NY, United States of America \\ 3 Climate and Global Dynamics Laboratory, National Center for Atmospheric Research, Boulder, CO, United States of America \\ 4 Institute for Atmospheric and Climate Science, ETH Zürich, Zurich, Switzerland \\ E-mail: dbonan@caltech.edu
}

Keywords: sea ice, climate change, uncertainty, projections

Supplementary material for this article is available online

\begin{abstract}
Improved knowledge of the contributing sources of uncertainty in projections of Arctic sea ice over the 21 st century is essential for evaluating impacts of a changing Arctic environment. Here, we consider the role of internal variability, model structure and emissions scenario in projections of Arctic sea-ice area (SIA) by using six single model initial-condition large ensembles and a suite of models participating in Phase 5 of the Coupled Model Intercomparison Project. For projections of September Arctic SIA change, internal variability accounts for as much as $40 \%-60 \%$ of the total uncertainty in the next decade, while emissions scenario dominates uncertainty toward the end of the century. Model structure accounts for $60 \%-70 \%$ of the total uncertainty by mid-century and declines to $30 \%$ at the end of the 21 st century in the summer months. For projections of wintertime Arctic SIA change, internal variability contributes as much as $50 \%-60 \%$ of the total uncertainty in the next decade and impacts total uncertainty at longer lead times when compared to the summertime. In winter, there exists a considerable scenario dependence of model uncertainty with relatively larger model uncertainty under strong forcing compared to weak forcing. At regional scales, the contribution of internal variability can vary widely and strongly depends on the calendar month and region. For wintertime SIA change in the GreenlandIceland-Norwegian and Barents Seas, internal variability contributes $60 \%-70 \%$ to the total uncertainty over the coming decades and remains important much longer than in other regions. We further find that the relative contribution of internal variability to total uncertainty is state-dependent and increases as sea ice volume declines. These results demonstrate that internal variability is a significant source of uncertainty in projections of Arctic sea ice.
\end{abstract}

\section{Introduction}

The rapid loss of Arctic sea ice over the last few decades has been one of the most iconic symbols of anthropogenic climate change. Since the beginning of the satellite record, September Arctic sea-ice extent (SIE) has decreased by approximately $50 \%$ (Stroeve and Notz 2018) and experienced considerable thinning largely due to a lengthening of the melt season (Perovich and Polashenski 2012, Stroeve et al 2014). While state-of-the-art global climate models (GCMs) predict a decline of Arctic SIE throughout the 21st century, the exact amount of ice loss remains highly uncertain (Massonnet et al 2012, Notz et al 2020). Studies suggest that in the summertime the Arctic will most likely be 'ice free' by the end of the 21st century
(Jahn 2018, Niederdrenk and Notz 2018, Sigmond et al 2018) and could possibly be ice free as early as 2050 (Jahn 2018) or 2030 (Wang and Overland 2009). To improve projections of Arctic sea ice, the relative importance of the sources of uncertainty need to be characterized and if possible reduced, particularly at regional scales (Eicken 2013, Barnhart et al 2016, Årthun et al 2020).

Internal variability, which refers to natural fluctuations in climate that occur even in the absence of external forcing, has long been known as an important source of uncertainty in projections of future climate (Hawkins and Sutton 2009, Deser et al 2012, 2020, Lehner et al 2020, Maher et al 2020). These fluctuations-intrinsic to the climate system-have been shown to exert a strong influence on short-term 
trends in numerous climate variables, such as surface temperature (Wallace et al 2012, Smoliak et al 2015, Deser et al 2016, Lehner et al 2017), precipitation (Hawkins and Sutton 2011, Deser et al 2012), snowpack (Siler et al 2019), glacier mass balance (Marzeion et al 2014, Bonan et al 2019, Roe et al 2020), ocean biogeochemical properties (Lovenduski et al 2016, Schlunegger et al 2020), and sea ice (Kay et al 2011, Swart et al 2015, Jahn et al 2016, Rosenblum and Eisenman 2017, Screen and Deser 2019, Ding et al 2019, England et al 2019, Landrum and Holland 2020). Recent estimates suggest that internal variability has contributed to approximately $50 \%$ of the observed trend in September Arctic SIE decline since 1979 (Stroeve et al 2007, Kay et al 2011, Zhang 2015, Ding et al 2017, 2019) and has strongly controlled regional patterns of sea ice loss (England et al 2019).

The large role of internal variability in determining changes to Arctic SIE over the observational record means the predictability of future Arctic SIE at decadal timescales could remain heavily influenced by internal variability. The advent of decadal prediction systems (e.g. Meehl et al 2009, 2014) raises the question whether realistic physics together with proper initialization of observations can lead GCMs to successfully constrain this internal variability and result in skillful estimates of SIE at decadal lead times (Koenigk et al 2012, Yang et al 2016). Initial-value predictability of Arctic SIE has been shown to be regionally and seasonally dependent (Blanchard-Wrigglesworth et al 2011b, Bushuk et al 2019), often only lasting a few years at most for total Arctic SIE (Blanchard-Wrigglesworth et al 2011a, Guemas et al 2016). Yet, using a suite of perfect model experiments (which quantify the upper limits of predictability), Yeager et al (2015) showed that the rate of sea ice loss in the North Atlantic may slow down in the coming decades due to a reduction of ocean heat transport into the Arctic, which itself is highly predictable. Similarly, Koenigk et al (2012) found a link between meridional overturning circulation and the potential predictability of decadal mean sea ice concentration (SIC) in the North Atlantic-consistent with Yang et al (2016). However, even if uncertainty due to internal variability cannot be reduced, understanding its magnitude will allow for better decision making in light of that uncertainty. This raises an important question: what is the relative role of internal variability in future projections of Arctic sea ice? Any accounting for the sources of uncertainty in projections of Arctic SIE must quantify the relative importance of each source at different spatial and temporal scales. For example, how important is internal variability for projections of Arctic sea ice 15 versus 30 years from now? Moreover, because models exhibit different magnitudes of internal variability in sea ice, both at pan-Arctic (e.g. Notz et al 2020, Olonscheck and Notz 2017) and regional scales (e.g.
England et al 2019, Topál et al 2020) such quantification must sample the influence of model uncertainty in the estimate of internal variability itself.

To examine these questions we use an unprecedented suite of single model initial-condition large ensembles (SMILEs) from six fully-coupled GCMs. Due to their sample size, these SMILEs uniquely allow us to partition uncertainty in projections of Arctic sea-ice area (SIA) into the relative roles of internal variability, model structure, and emissions scenario at both Arctic-wide and regional spatial scales without relying on statistical representations of the forced response or internal variability (e.g. Lique et al 2016). The SMILEs also allow us to quantify the influence of different estimates of internal variability, a feature of sea ice projection uncertainty that has received little attention. In what follows, we first investigate the role of internal variability in projections of total Arctic SIA change. We then explore how the relative partitioning of each source changes as a function of season and Arctic region and how this partitioning is influenced by the mean-state of Arctic sea ice.

\section{Data}

\subsection{Observational data sets}

Monthly Arctic SIA from 1979 to 2020 was derived using observations of monthly SIC from the National Snow and Ice Data Center passive microwave retrievals bootstrap algorithm (Comiso et al 2017). A reconstruction of monthly Arctic SIA (Walsh et al 2017) is used to analyze variability over a longer observational period. We choose to begin with the year 1930 from the reconstruction to account for uncertainties and sparse data coverage prior to the 1930s.

\subsection{MMLEA output}

We use six SMILEs from the Multi-Model Large Ensemble Archive (MMLEA; Deser et al 2020) to investigate the role of internal variability on projections of Arctic sea ice. These include the: 40member Community Earth System Model Large Ensemble Community Project (CESM1-LE; Kay et al 2015), 50-member Canadian Earth System Model Large Ensemble (CanESM2-LE; KirchmeierYoung et al 2017), 30-member Commonwealth Scientific and Industrial Research Organisation Large Ensemble (CSIRO-Mk3.6.0-LE; Jeffrey et al 2013), 20-member Geophysical Fluid Dynamics Laboratory Large Ensemble (GFDL-CM3-LE; Sun et al 2018), 30-member Geophysical Fluid Dynamics Laboratory Earth System Model Large Ensemble (GFDL-ESM2M-LE; Rodgers et al 2015), and 100member Max Planck Institute Grand Ensemble (MPI-GE; Maher et al 2019). Each SMILE uses historical and RCP8.5 forcing. We also use the RCP2.6 and RCP4.5 100-member ensembles from the MPI-GE. From each SMILE we use SIC to compute monthly Arctic SIA for six Arctic regions and 
the pan-Arctic (see figure S1 (available online at stacks.iop.org/ERL/16/044002/mmedia)). We also use sea ice thickness to compute monthly Arctic seaice volume (SIV) for these same spatial domains. Note that the output from GFDL-CM3 and GFDLESM2M is the average thickness over the ice-covered area of the grid cell. To compute SIV, the monthly averaged ice-covered thickness from both models was multiplied by the monthly average SIC of each cell to get the grid-cell average SIT. Prior to these calculations, all model output is regridded to a common $1^{\circ} \times 1^{\circ}$ analysis grid using nearest-neighbor interpolation. We choose SIA since SIE can be more grid-size dependent (Notz 2014).

\subsection{CMIP5 output}

We use monthly output from the historical, RCP2.6, RCP4.5, and RCP8.5 simulations of 18 different GCMs participating in CMIP5 (Taylor et al 2012). Since the historical simulations end in 2005, we merge the 1850-2005 fields from the historical simulations with the 2006-2100 fields under each RCP forcing scenario. For each experiment, we use SIC to compute monthly Arctic SIA. The set of GCMs evaluated reflects those that provide the necessary output for each RCP scenario (see table S1). All model output is regridded to a common $1^{\circ} \times 1^{\circ}$ analysis grid using nearest-neighbor interpolation.

\section{Uncertainty in projections of Arctic sea ice}

We begin by partitioning three sources of uncertainty following Hawkins and Sutton (2009) and Lehner et al (2020), where the total uncertainty (T) is the sum of the uncertainty due to model structure $(M)$, the uncertainty due to internal variability $(I)$ and the uncertainty due to emissions scenario $(S)$. Each source can be estimated for a given time $t$ and location $x$ such that:

$$
T(t, x)=I(t, x)+M(t, x)+S(t, x)
$$

where the fractional uncertainty from a given source is calculated as $I / T, M / T$, and $S / T$. $I$ is calculated as the variance across ensemble members of each SMILE, yielding one time-varying estimate of $I$ per SMILE. Note, $I$ is computed across RCP8.5 forcing scenarios only. Averaging across the six $I$ yields the multi-model mean internal variability uncertainty (see upper bold white lines in figures $1(\mathrm{c})$ and (d)). To quantify the influence of model uncertainty in the estimate of $I$ we also use the model with the largest and smallest $I$ (see white shaded regions in figure 1). Model uncertainty in the estimate of $I$ has emerged as an important and potentially reducible source of uncertainty in regional temperature and precipitation changes (Deser et al 2020, Lehner et al 2020) and projections of global ocean biogeochemical properties
(Schlunegger et al 2020). $M$ is calculated as the variance across the ensemble means of the six SMILEs under RCP8.5 forcing. It is important to note that the SMILEs used in this study are found to be reasonably representative of the CMIP5 inter-model spread for the percent of remaining Arctic sea ice cover (see figures 1 and S2), but a more systematic comparison is necessary before generalizing this conclusion. Finally, since only a few of the SMILEs were run with more than one emissions scenario, we turn to CMIP5 for $S$, which is calculated as the variance across the multimodel mean RCP scenarios (see table S1 for details). We include CMIP5 models that contain all three forcing scenarios (RCP2.6, RCP4.5, RCP8.5) to mitigate the influence of model structure in the estimate of $S$. This resulted in 18 CMIP5 models (see table S1). Prior to these variance calculations, the monthly SIA was smoothed with a 5-year running mean to isolate the effect of uncertainty on short-term projections and then used to calculate the percent of remaining sea ice relative to the mean of each simulation from 1995 to 2014 (see figure S2) following Boé et al (2009). Thus, importantly, this study examines 'response' uncertainty relative to a reference period, which differs from absolute uncertainty. Focusing on response uncertainty rather than absolute uncertainty removes the confounding issue of model differences due to mean state biases and may also help elucidate why models have different sea ice sensitivities to carbon-dioxide emissions and warming (Winton 2011, Notz and Stroeve 2016, Notz et al 2020).

\subsection{Total Arctic SIA}

We first consider projections of Arctic SIA change in September (the seasonal minimum) and March (the seasonal maximum). Figure 1 shows the fractional contribution of each source of uncertainty to total uncertainty. In September, uncertainty due to internal variability is important initially, accounting for approximately $40 \%$ of total uncertainty. However, over time model uncertainty increases and eventually dominates for the first half of the 21st century, before scenario uncertainty starts to dominate after approximately mid-century (figure 1(c)). However, model uncertainty in internal variability itself can have an effect on climate projections (e.g. Lehner et al 2020). Accounting for the minimum and maximum contribution of internal variability to total uncertainty suggests that internal variability could account for as much as $40 \%-60 \%$ or as little as $10 \%-20 \%$ of total uncertainty in projections of September SIA change in the coming decades and could contribute approximately $10 \%$ throughout the 21 st century. Note, these results are similar for most summer months and summertime averages (see figures S4 and S5).

A different story emerges for projections of Arctic SIA change in March. While uncertainty due to internal variability is again important initially and accounts for more of the total uncertainty at longer 

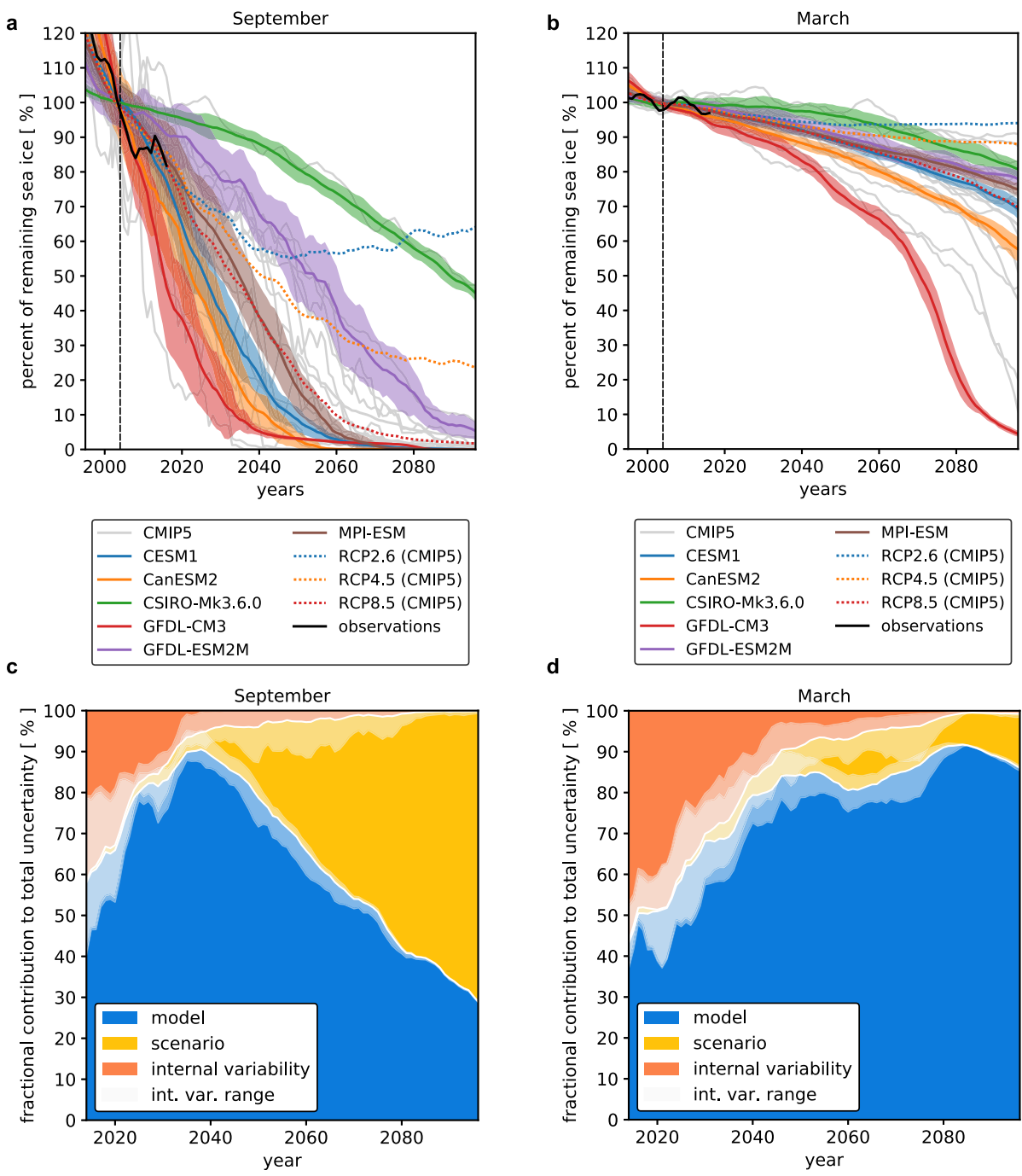

Figure 1. (a), (b) Percent of remaining sea ice for each single-model initial condition large ensemble (SMILE) and the available CMIP5 output relative to 1995-2014 under historical and RCP8.5 forcing for (a) September and (b) March. Both panels are for five-year mean projections. The bold line represents the ensemble-mean of each SMILE and the shading represents the standard deviation of each SMILE under historical and RCP8.5 forcing. The colored dotted lines represent the multi-model mean of each RCP scenarios from 18 CMIP5 models. The gray lines represent the 18 CMIP5 models under RCP8.5. The black line denotes observations from 1979 to 2020. (c), (d) Fractional contribution of model structure, emissions scenario, and internal variability to total uncertainty for the percent of remaining Arctic sea ice cover in (c) September and (d) March. The solid white lines denote the borders between each source of uncertainty, while the transparent white shading around those lines is the range of this estimate based on different estimates of internal variability in the MMLEA. Both fractional uncertainty panels are for five-year mean projections of percent of remaining Arctic sea-ice cover relative to 1995-2014.

lead times, model uncertainty increases and quickly dominates until the end of the century (figure $1(\mathrm{~d})$ ). Scenario uncertainty is relatively less important for projections of Arctic SIA change in March and, more broadly, during the wintertime (see figure S4). This differs slightly from the results of Notz et al (2020), which find a larger role for scenario uncertainty. These differences likely arise through our formulation of uncertainty due to emissions scenario and model structure as response uncertainty rather than absolute uncertainty. In winter, model uncertainty is large and diminishes scenario uncertainty in relative terms. Another caveat is that in winter the model uncertainty across SMILEs is larger and less representative of the model uncertainty across CMIP5 models. As a consequence, the relative contribution of scenario uncertainty in SMILEs is seemingly small and only about half of what it would be if model uncertainty had been taken from CMIP5 (see below for more discussion). Uncertainty in model internal variability remains large throughout the 21 st century, suggesting internal variability could account for as much as $20 \%$ or as little as $5 \%$ of the total uncertainty beyond midcentury. The relative partitioning is similar for most winter months and wintertime averages (see figures S4 and S5).

We also calculate model uncertainty using CMIP5 models from the RCP2.6, RCP4.5 and RCP8.5 scenarios to examine the effect of weak forcing and thus weaker model response uncertainty for the late $21 \mathrm{st}$ century (see figure S6). To do this, we calculate the variance across models for each RCP scenario, which 


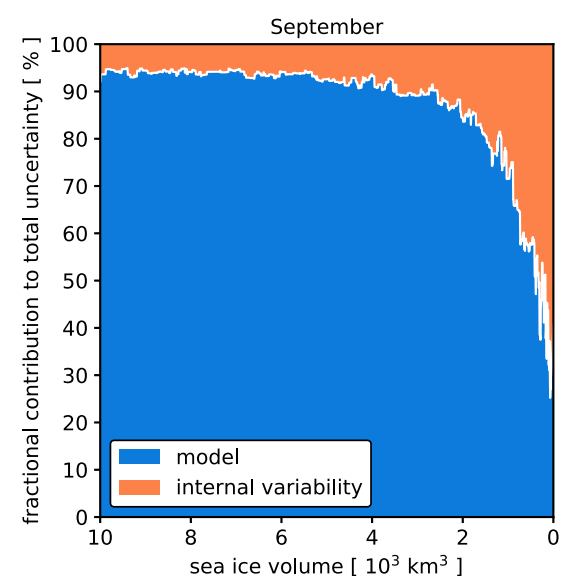

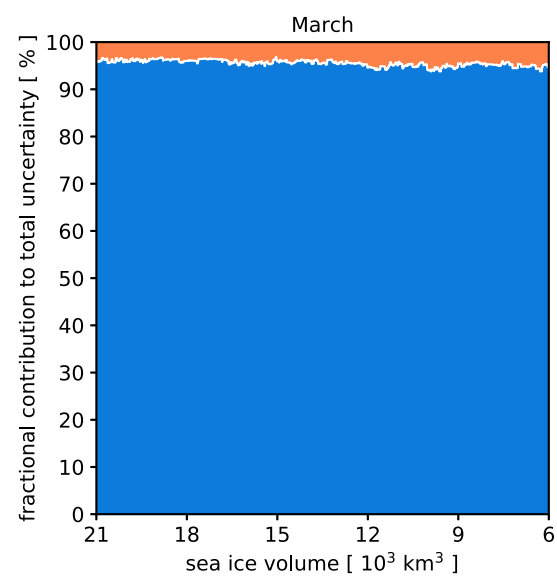

Figure 2. Fractional contribution of model structure and internal variability to total uncertainty for Arctic sea-ice area (SIA) in (a) September and (b) March as a function of Arctic sea-ice volume (SIV). The solid white lines denotes the border between the two sources of uncertainty. Both fractional uncertainty panels are for projections of Arctic SIA with no temporal averaging or reference period. Note the $x$-axis is different for (a) and (b).

results in an estimate of model uncertainty for three RCP scenarios. This formulation of model uncertainty combines the influence of model uncertainty and internal variability, but we expect the confounding influence of internal variability to be very small across 2070-2100 averages. In general, we find only small differences in the estimate of model uncertainty for RCP8.5 and the SMILEs, suggesting these models are indeed representative of the CMIP5 models when compared for the same scenario. As discussed in the previous paragraph, in late winter, the contribution of scenario uncertainty to total uncertainty nearly doubles when using CMIP5 RCP8.5 instead of the SMILEs, likely reflecting the fact that the SMILEs are less representative of winter sea ice behavior when compared to the CMIP5 models. Furthermore, there is a clear scenario dependence of model uncertainty in winter months, with larger values for RCP8.5 than for RCP4.5 and RCP2.6 (see figure S6). At the end of the 21 st century, model uncertainty estimated from RCP 2.6 accounts for only $40 \%$ of the total uncertainty whereas from RCP8.5 it accounts for $90 \%$ of the total uncertainty. In summer, model uncertainty is similar across each RCP scenario (see figure S6) largely because model uncertainty is saturated as SIA goes to zero. Thus, there is an inherent limitation in our formulation of $M$ as it is strongly dependent on the emission scenario, particularly in winter when enough sea ice remains for model differences to become more clear under strong compared to weak radiative forcing. Furthermore, examining the uncertainty partitioning without 5 -year running averages shows that the relative role of internal variability in projection uncertainty can increase by approximately $10 \%-20 \%$ in the first decade across all months (see figure S7).

These results suggest that uncertainty in shortterm projections of Arctic SIA change, regardless of the season, is dominated by internal variability, while for long-term projections of Arctic sea ice, both scenario and model uncertainty become important. At long lead times, scenario uncertainty accounts for most of the uncertainty in projections of Arctic SIA change in the summer months and model uncertainty accounts for most of the uncertainty in projections of Arctic SIA change in the winter months. This likely reflects the fact that September Arctic SIA disappears in most GCMs by 2100 under RCP8.5.

\subsection{State dependence of internal variability}

These results show a clear time-scale dependence for the relative importance of internal variability in uncertainty of projections of Arctic SIA change. However, recent studies have shown that the internal variability and the predictability of Arctic sea ice can change over time and under anthropogenic forcing (Goosse et al 2009, Holland et al 2019, Mioduszewski et al 2019). September Arctic SIA variability is expected to increase under warming (Goosse et al 2009, Mioduszewski et al 2019), suggesting that the role of internal variability in sea ice projections is mean-state dependent. To investigate the role of internal variability in projections of Arctic sea ice as a function of the mean-state, we partition the relative sources of uncertainty with respect to SIV by binning a given SIA to its associated SIV for each month. We then perform the same variance analysis described above as a function of SIV instead of as a function of time. Doing this for each SMILE member and the ensemble-mean of each SMILE allows us to examine the contributing sources of uncertainty as a function of SIV.

Figure 2 shows the fractional contribution of internal variability and model structure to total uncertainty for future Arctic SIA in September and March as a function of September and March 

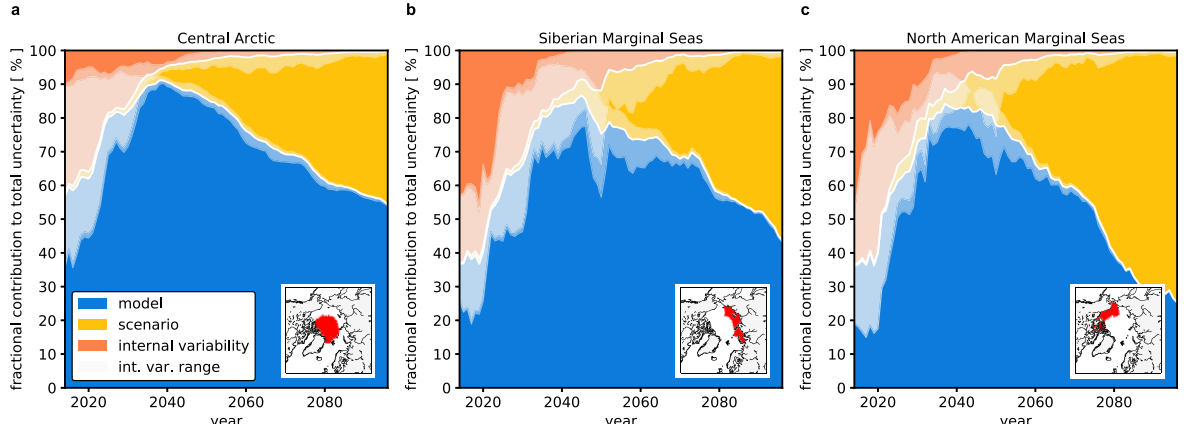

Figure 3. Fractional contribution of model structure, emissions scenario, and internal variability to total uncertainty for percent of remaining sea ice cover in July, August and September (JAS) for the Central Arctic, Siberian Marginal Seas (Kara Sea, Laptev Sea, East Siberian Sea), and North American Marginal Seas (Chukchi Sea, Beaufort Sea, Canadian Archipelago). The solid white lines indicate the borders between sources of uncertainty, while the transparent white shading around those lines is the range of this estimate based on different estimates of internal variability in the MMLEA. All panels are for five-year mean projections of percent of remaining Arctic sea-ice cover relative to 1995-2014.

Arctic SIV, respectively. Note, scenario uncertainty was excluded in these calculations (by using simulations from RCP 8.5 only) to isolate the effect of internal variability at different mean-states with respect to model uncertainty under the same meanstate. In September, as SIV declines-which is expected to occur throughout the 21st century-internal variability remains constant for most SIV values, accounting for approximately $10 \%$ of total uncertainty. However, at lower SIV regimes $\left(<3000 \mathrm{~km}^{3}\right)$, the contribution of internal variability increases and accounts for approximately $80 \%$ of the total uncertainty at low thickness sea ice regimes (i.e. SIV < $1000 \mathrm{~km}^{3}$ ). This is consistent with previous work that has shown increased variability of summer Arctic SIA as it declines (e.g. Mioduszewski et al 2019). Note, this result does not refer to when the maximum SIA variability occurs $\left(\approx 3-4\right.$ million $\left.\mathrm{km}^{2}\right)$, but at which mean state the relative contribution of internal variability to projection uncertainty is largest. In March, the contribution of internal variability to total uncertainty remains relatively constant at all SIV regimes, likely reflecting the fact that sea ice is present in most winter climates in future projections (e.g. Goosse et al 2009). It is important to note that this increase in the contribution of internal variability to uncertainty at lower SIV regimes holds for summer (June, July, and August) months (not shown).

\subsection{Regional Arctic SIA}

While the loss of total Arctic SIA is important for understanding the global climate response, climate change and sea ice loss are experienced predominately at regional scales (Barnhart et al 2014, Lehner and Stocker 2015). To investigate uncertainty in regional SIA projections, we compute SIA for six Arctic regions, which include the Central Arctic, Siberian Marginal Seas, North American Marginal Seas, Baffin/Hudson Bay and the Labrador
Sea, the Bering Sea and Sea of Okhotsk, and Greenland-Iceland-Norwegian (GIN) and Bering Seas. These regions were chosen to represent geographically distinct parts of the Arctic ocean, where SIA retreat occurs with different velocities. As with total Arctic SIA change, the SMILEs used in this study are found to be reasonably representative of the CMIP5 inter-model spread for the percent of remaining Arctic sea ice cover in each region (see figure S3).

Figure 3 shows the fractional contribution of each source of uncertainty to total uncertainty in projections of July, August, and September SIA change in the Central Arctic (figure 3(a)), Siberian Marginal Seas (figure 3(b)), and North American Marginal Seas (figure 3(c)). We only show summertime SIA change as these regions are fully ice covered in the wintertime and exhibit little wintertime variability throughout much of the 21st century. As with total September Arctic SIA change, there is a large role for internal variability initially, accounting for approximately $40 \%$ of total uncertainty in the Central Arctic (figure $3(\mathrm{a})$ ) and $60 \%$ in the Siberian and North American Marginal Seas (figures 3(b) and (c)). However, over time model uncertainty increases and eventually dominates for the first half of the 21st century in Central Arctic (figure 3(a)) and marginal seas (figures 3(b) and (c)), accounting for $60 \%-70 \%$ of the total uncertainty. Note, the contribution of model structure to total uncertainty at the end of the century is lowest for the North American Marginal Seas. By the end of the 21st century scenario uncertainty dominates and accounts for over half of the uncertainty, meaning that whether or not an ice free Arctic occurs in the summertime may be a direct consequence of climate change policy. Notably, the intermodel range of simulated internal variability contributions remains larger through the 21st century in each region when compared to total Arctic SIA change. 

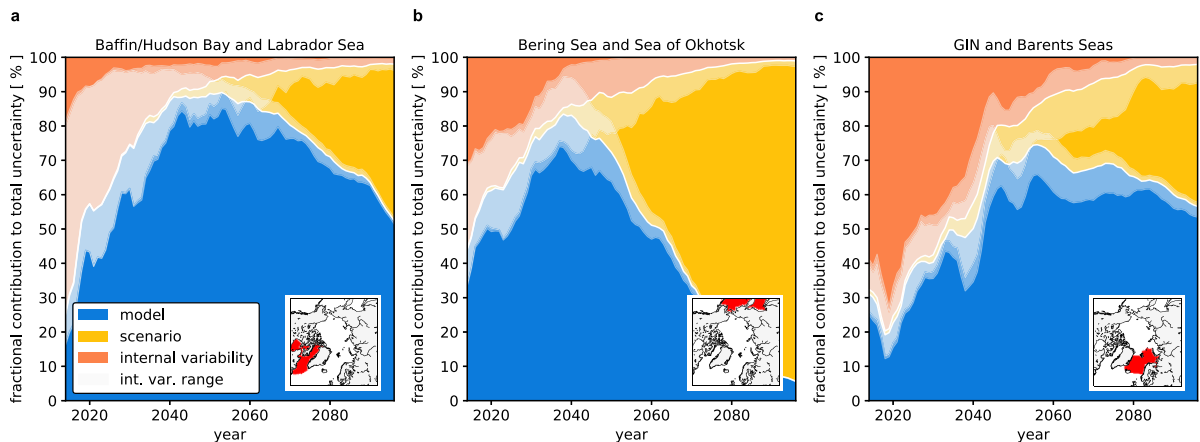

Figure 4. Fractional contribution of model structure, emissions scenario, and internal variability to total uncertainty for percent of remaining sea ice cover in January, February, and March (JFM) for (a) Baffin Bay, Hudson Bay, and the Labrador Sea, (b) being Sea and Sea of Okhotsk, and the (c) GIN and Barents Seas. The solid white lines indicate the borders between sources of uncertainty, while the transparent white shading around those lines is the range of this estimate based on different estimates of internal variability in the MMLEA. All panels are for five-year mean projections of percent of remaining Arctic sea-ice cover relative to $1995-2014$.

Figure 4 shows the fractional contribution of each source of uncertainty to total uncertainty in projections of January, February, and March Arctic SIA change in Baffin Bay, Hudson Bay and the Labrador Sea (figure 4(a)), Bering Sea and Sea of Okhotsk (figure 4(b)), and GIN and Barents Seas (figure 4(c)). These regions were selected to examine wintertime SIA change as there is highly variable SIA in winter and little-to-no SIA in summer. As with regions of variable summer sea ice cover, these regions show a distinct pattern of uncertainty partitioning. For Baffin Bay, Hudson Bay, and Labrador Sea, approximately $80 \%$ of total uncertainty in the next decade is attributable to internal variability. Note that the contribution of uncertainty in the estimate of internal variability itself can cause this to change to only $20 \%$ (mainly driven by CSIRO-Mk3.6.0 which exhibits less internal variability of SIA). The internal variability contribution diminishes to approximately $10 \%$ by the end of the century, and model structure dominates by 2030. A similar picture emerges for the Bering Sea and Sea of Okhotsk, but instead scenario uncertainty dominates in the latter half of the 21st century. Interestingly, the uncertainty partitioning for the GIN and Barents Seas has a distinct structure: internal variability dominates projection uncertainty for the next 30 years and remains persistent throughout much of the 21 st century. The contribution of internal variability is notably larger than in other regions and is most likely related to the influence of Atlantic heat transport on sea ice (Årthun et al 2012). This contribution also suggests that since sea-surface temperature is much more predictable in the North Atlantic when compared to other regions on decadal timescales (Pohlmann et al 2004), so too is Arctic sea ice. Another explanation for the larger role of internal variability could be that Atlantic multidecadal variability is thought to play a primary role in determining the sea ice edge in this region, particularly in winter when it reaches into the zone of influence of multidecadal North Atlantic sea-surface temperature variability (Goessling et al 2016).

A key result here-in contrast to total Arctic SIA change for March and September-is the larger role of internal variability in contributing to total uncertainty, which persists throughout much of the 21st century. This suggests decadal predictions of regional Arctic SIA will be highly influenced by internal variability, especially for wintertime conditions in the GIN and Barents Seas-consistent with Årthun et al (2020). Moreover, the range of internal variability across models presents a unique challenge as internal variability could account for as much as $80 \%$ or as little as $20 \%$ of the total uncertainty in regions like the Labrador Sea in the coming decades. Understanding the cause of the range in this internal variability uncertainty is an important next step, whether it is related to model biases in the representation of Atlantic multidecadal variability or dependent on the sea ice mean-state.

\subsection{Reducing the inter-model spread of internal variability}

A unique result of this analysis is the partitioning of uncertainty due to different estimates of internal variability, which varies considerably across GCMs (see figure 1). This suggests that at least some GCMs are biased in their magnitude of variability. Due to the short observational record, it is difficult to precisely estimate the real-world magnitude of SIA internal variability (e.g. Brennan et al 2020). However, using a reconstruction of September Arctic SIA back to 1930 (Walsh et al 2017) we try to estimate historical Arctic SIA variability. To do this, we calculate nonoverlapping 5-year trends of September Arctic SIA in observations and models. Figure 5 shows histograms of separate 5-year trends in September Arctic SIA from 1950 to 2019 using all members of each 


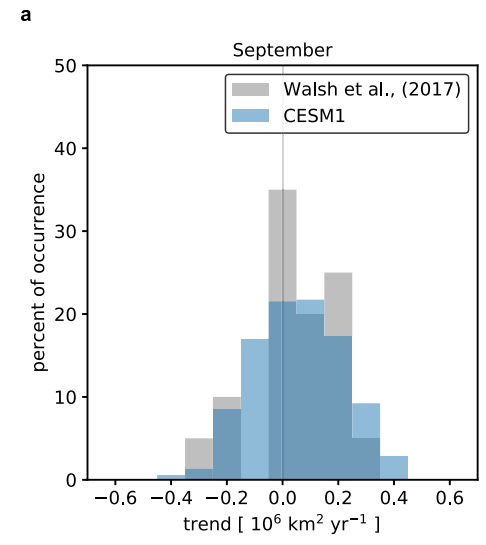

d

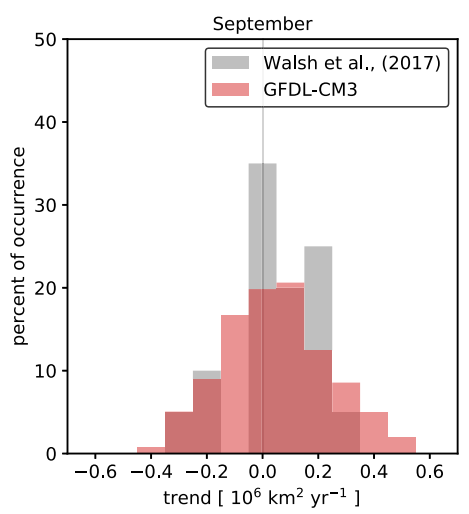

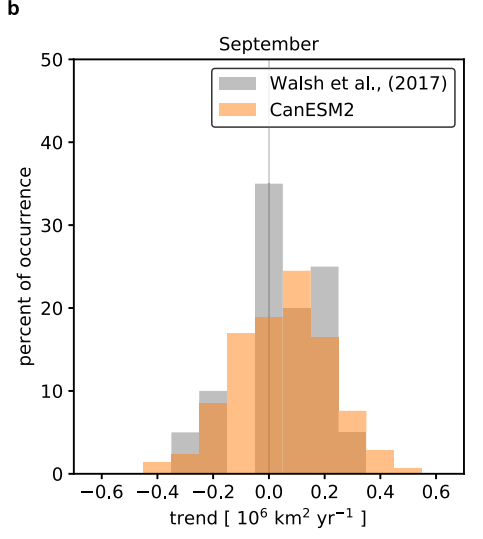

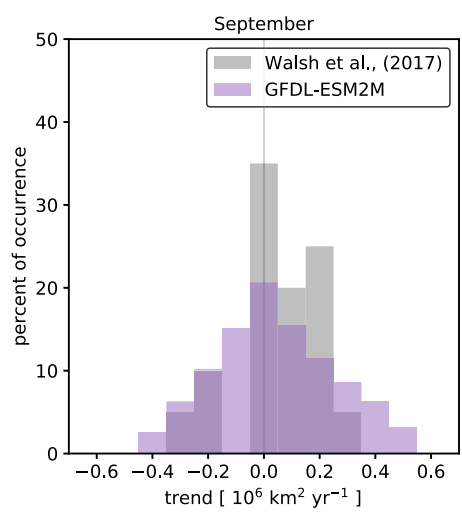

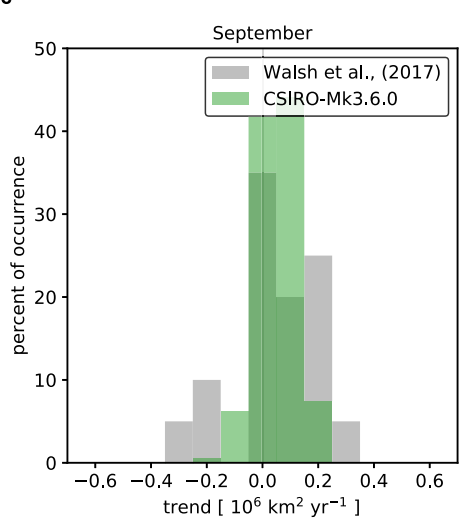

f

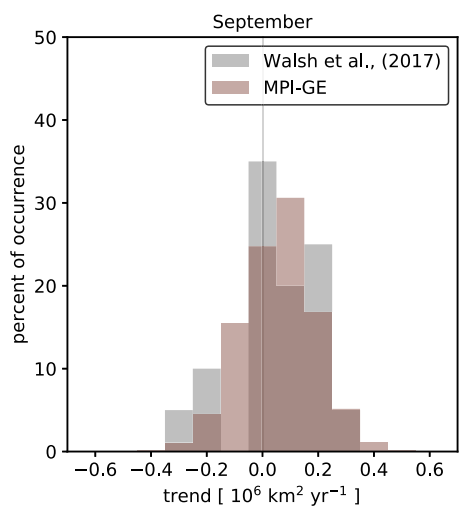

Figure 5. Percent of occurrence of non-overlapping 5-year trends in September Arctic sea-ice area (SIA) from 1950 to 2019 for the (a) CESM1, (b) CanESM2, (c) CSIRO-Mk3.6.0, (d) GFDL-CM3, (e) GFDL-ESM2M, and (f) MPI-ESM. A 4th order polynomial was removed from each member of each SMILE prior to trend calculations to estimate the forced response. The bars show the distribution of trends for all members. The gray bars show percent of occurrence of non-overlapping 5-year trends in September Arctic SIA from 1930 to 2017 as estimated from Walsh et al (2017). A 4th order polynomial was also removed from the dataset prior to trend calculations to estimate the forced response.

SMILE. A 4th order polynomial was used to approximate and remove the forced response consistently in both observations and models. The gray bars indicate the range from Walsh et al (2017) using separate 5 -year trends from 1930 to 2019. While most models appear to span the range of internal variability in the historical record, CSIRO-Mk3.6.0 does not simulate a large enough range of 5-year trends, most likely reflecting the fact that sea ice is biased high throughout the summer. This suggests the lowest contribution of internal variability to total uncertainty in projections September Arctic SIA change seen earlier in the paper is likely not realistic. Understanding and resolving these biases in internal variability across fully-coupled GCMs should remain a focus of the sea ice community as it is important for attribution of observed sea ice loss to anthropogenic climate change as well as for efforts of decadal prediction.

\section{Concluding remarks}

The impacts of Arctic sea ice loss will be predominately felt by coastal communities, making it crucial to quantify and reduce projection uncertainty at regional scales. Here, we used a suite of SMILEs to investigate the sources of uncertainty in projections of Arctic SIA change. For September SIA change, model structure contributes between $30 \%$ and $80 \%$ of the total uncertainty over the next century, while for March SIA change, model structure contributes approximately $40 \%-80 \%$ of the total uncertainty over the next century and accounts for more uncertainty at the end of the 21 st century. We find a clear timescale dependence for internal variability. For September SIA change, internal variability contributes approximately $40 \%-60 \%$ of total uncertainty in the next few decades, while for March SIA change-and winter SIA change more generally-internal variability contributes between $50 \%$ and $60 \%$ of total uncertainty and influences projections at longer lead times. Scenario uncertainty contributes mainly to uncertainty in summertime projections, accounting for approximately $70 \%$ of total uncertainty by the end of the century. The smaller contribution of scenario uncertainty to total uncertainty in winter likely reflects the fact that model uncertainty is so large that it diminishes scenario uncertainty in relative terms. It is important to note that in winter model uncertainty strongly depends on the emissions scenario used to calculate it, which may also affect estimates of the 
relative role of scenario uncertainty (see figure S6). We also find that the role for internal variability is mean-state dependent with thinner summer sea ice regimes more heavily influenced by internal variability, accounting for approximately $80 \%$ of total uncertainty for SIV $<1000 \mathrm{~km}^{3}$. At regional scales, the contribution of internal variability to total uncertainty increases, but has a large range and strongly depends on the month and region. In the GIN and Barents Seas, for instance, internal variability contributes approximately $50 \%-70 \%$ of the total uncertainty over the next 30 years, while for the Central Arctic, internal variability accounts for approximately $20 \%-30 \%$ of the total uncertainty. This is likely related to the influence of Atlantic heat transport on sea ice in the North Atlantic during the wintertime and multidecadal variability of North Atlantic sea-surface temperature.

An important result of this study is the intermodel spread in the contribution of internal variability to projection uncertainty. Recent work has highlighted the role of remote internal processes in determining sea ice trends across these same SMILEs (Topál et al 2020), but a more process-oriented analysis of the spatial and temporal timescales of this variability may better reveal the sources of intermodel spread. For instance, it has been shown that these remote processes are not stable on longer time scales (Bonan and Blanchard-Wrigglesworth 2020), suggesting that associated variability in September SIA during the satellite era does not paint a complete picture of the future SIA variability. The outsized role for internal variability in projections of Arctic sea ice changes in the coming decades further motivates the use of SMILEs to investigate a wide range of possible sequences of sea ice internal variability and its drivers. However, such work is beyond the scope of this paper, whose primary goal is to highlight the relative contribution of different sources of uncertainty to Arctic sea ice projections at different spatial and temporal scales.

While internal variability poses a great challenge for predicting Arctic SIA in the coming decades, the contribution of model structure to total uncertainty should not be ignored. So-called 'emergent constraints', which link the inter-model spread in climate projections to observable predictors, should be used when characterizing projection uncertainty. Indeed, model uncertainty has been reduced through observational constraints. Previous work has related the amount of future ice loss to the magnitude of historical SIA trends (Boé et al 2009, Hall et al 2019) and to the initial state of the sea ice (Bitz 2008, Massonnet et al 2012, Hall et al 2019) and the Arctic climate (Senftleben et al 2020), but open questions remain as to why these relationships exist and persist throughout the next century. Further comparison of new and old generations of climate models may better reveal the sources of this spread. Understanding biases in these trends (e.g. Rosenblum and Eisenman 2016, Rosenblum and Eisenman 2017) and the physical mechanisms behind these constraints will improve the reliability of sea ice projections and increase confidence in our understanding of what controls the rate of Arctic sea ice loss.

\section{Data availability statement}

The data that support the findings of this study are openly available at the following URLs: https:// esgf-node.llnl.gov/search/cmip5/ and www.cesm. ucar.edu/projects/community-projects/MMLEA/.

\section{Acknowledgments}

The authors thank the US CLIVAR Working Group on Large Ensembles for making the output publicly available. The authors also thank the climate modeling groups for producing and making available their output. This work was greatly improved through discussions with Mitch Bushuk and comments from Tapio Schneider and Katie Brennan. The authors are grateful for helpful comments from Dirk Notz and one anonymous reviewer, as well as the Editor. D B B was supported by an American Meteorological Society (AMS) Graduate Fellowship. F L was supported by the Swiss National Science Foundation Ambizione Fellowship (Project PZ00P2_174128) and the Regional and Global Model Analysis (RGMA) component of the Earth and Environmental System Modeling Program of the U.S. Department of Energy's Office of Biological \& Environmental Research (BER) via NSF IA 1844590. Contributions from M M H were supported by the National Center for Atmospheric Research (NCAR), which is a major facility sponsored by the NSF under Cooperative Agreement No. 1852977.

\section{ORCID iDs}

David B Bonan (ㄱ) https://orcid.org/0000-0003-

3867-6009

Flavio Lehner (ㄱ) https://orcid.org/0000-0003-46329701

Marika M Holland (1) https://orcid.org/0000-00015621-8939

\section{References}

Årthun M, Eldevik T, Smedsrud L, Skagseth $\varnothing$ and Ingvaldsen R 2012 Quantifying the influence of Atlantic heat on Barents Sea ice variability and retreat J. Clim. 25 4736-43

Årthun M, Onarheim I H, Dörr J and Eldevik T 2020 The seasonal and regional transition to an ice-free Arctic Geophys. Res. Lett. 48 e2020GL090825

Barnhart K R, Miller C R, Overeem I and Kay J E 2016 Mapping the future expansion of Arctic open water Nat. Clim. Change $6280-5$

Barnhart K R, Overeem I and Anderson R S 2014 The effect of changing sea ice on the physical vulnerability of Arctic coasts Cryosphere 8 1777-99 
Bitz C M 2008 Some aspects of uncertainty in predicting sea ice thinning Arctic Sea Ice Decline: Observations Projections Mechanisms Implications Geophys. Monogr 180 63-76

Blanchard-Wrigglesworth E, Armour K C, Bitz C M and DeWeaver E 2011a Persistence and inherent predictability of Arctic sea ice in a GCM ensemble and observations J. Clim. 24 231-50

Blanchard-Wrigglesworth E, Bitz C and Holland M 2011b Influence of initial conditions and climate forcing on predicting Arctic sea ice Geophys. Res. Lett. 38 L18503

Boé J, Hall A and Qu X 2009 September sea-ice cover in the Arctic Ocean projected to vanish by 2100 Nat. Geosci. 2 341-3

Bonan D B and Blanchard-Wrigglesworth E 2020 Nonstationary teleconnection between the Pacific Ocean and Arctic sea ice Geophys. Res. Lett. 47 e2019GL085666

Bonan D B, Christian J E and Christianson K 2019 Influence of North Atlantic climate variability on glacier mass balance in Norway, Sweden and Svalbard J. Glaciol. 65 580-94

Brennan M K, Hakim G J and Blanchard-Wrigglesworth E 2020 Arctic sea-ice variability during the instrumental era Geophys. Res. Lett. 47 e2019GL086843

Bushuk M, Msadek R, Winton M, Vecchi G, Yang X, Rosati A and Gudgel R 2019 Regional Arctic sea-ice prediction: potential versus operational seasonal forecast skill Clim. Dyn. 52 2721-43

Deser C et al 2020 Insights from Earth system model initial-condition large ensembles and future prospects Nat Clim. Change 10 277-86

Deser C, Phillips A, Bourdette V and Teng H 2012 Uncertainty in climate change projections: the role of internal variability Clim. Dyn. 38 527-46

Deser C, Terray L and Phillips A S 2016 Forced and internal components of winter air temperature trends over North America during the past 50 years: mechanisms and implications J. Clim. 29 2237-58

Ding Q et al 2017 Influence of high-latitude atmospheric circulation changes on summertime Arctic sea ice Nat. Clim. Change 7 289-95

Ding Q et al 2019 Fingerprints of internal drivers of Arctic sea ice loss in observations and model simulations Nat. Geosci. 12 28-33

Eicken H 2013 Arctic sea ice needs better forecasts Nature 497 431-3

England M, Jahn A and Polvani L 2019 Nonuniform contribution of internal variability to recent Arctic sea ice loss J. Clim. 32 4039-53

Goessling H F, Tietsche S, Day J J, Hawkins E and Jung T 2016 Predictability of the Arctic sea ice edge Geophys. Res. Lett. 43 1642-50

Goosse H, Arzel O, Bitz C M, de Montety A and Vancoppenolle M 2009 Increased variability of the Arctic summer ice extent in a warmer climate Geophys. Res. Lett. 36

Guemas V et al 2016 A review on Arctic sea-ice predictability and prediction on seasonal to decadal time-scales Q. J. R. Meteorol. Soc. 142 546-61

Hall A, Cox P, Huntingford C and Klein S 2019 Progressing emergent constraints on future climate change Nat. Clim. Change 9 269-78

Hawkins E and Sutton R 2009 The potential to narrow uncertainty in regional climate predictions Bull. Am. Meteorol. Soc. 90 1095-108

Hawkins E and Sutton R 2011 The potential to narrow uncertainty in projections of regional precipitation change Clim. Dyn. 37 407-18

Holland M M, Landrum L, Bailey D and Vavrus S 2019 Changing seasonal predictability of Arctic summer sea ice area in a warming climate J. Clim. 32 4963-79

Jahn A 2018 Reduced probability of ice-free summers for 1.5 C compared to $2 \mathrm{C}$ warming Nat. Clim. Change 8 409-13

Jahn A, Kay J E, Holland M M and Hall D M 2016 How predictable is the timing of a summer ice-free Arctic? Geophys. Res. Lett. 43 9113-20
Jeffrey S, Rotstayn L, Collier M, Dravitzki S, Hamalainen C, Moeseneder C, Wong K and Syktus J 2013 Australia's CMIP5 submission using the CSIRO-Mk3. 6 model Aust. Meteor. Oceanogr. J 63 1-13

Kay J E et al 2015 The Community Earth System Model (CESM) large ensemble project: a community resource for studying climate change in the presence of internal climate variability Bull. Am. Meteorol. Soc. 96 1333-49

Kay J E, Holland M M and Jahn A 2011 Inter-annual to multi-decadal Arctic sea ice extent trends in a warming world Geophys. Res. Lett. 38 L15708

Kirchmeier-Young M C, Zwiers F W and Gillett N P 2017 Attribution of extreme events in Arctic sea ice extent J. Clim. 30 553-71

Koenigk T, Beatty C K, Caian M, Döscher R and Wyser K 2012 Potential decadal predictability and its sensitivity to sea ice albedo parameterization in a global coupled model Clim. Dyn. 38 2389-408

Landrum L and Holland M M 2020 Extremes become routine in an emerging new Arctic Nat. Clim. Change $101108-1115$

Lehner F, Deser C, Maher N, Marotzke J, Fischer E M, Brunner L, Knutti R and Hawkins E 2020 Partitioning climate projection uncertainty with multiple large ensembles and CMIP5/6 Earth Syst. Dyn. 11 491-508

Lehner F, Deser C and Terray L 2017 Toward a new estimate of 'time of emergence' of anthropogenic warming: insights from dynamical adjustment and a large initial-condition model ensemble J. Clim. 30 7739-56

Lehner F and Stocker T F 2015 From local perception to global perspective Nat. Clim. Change 5 731-4

Lique C, Holland M M, Dibike Y B, Lawrence D M and Screen J A 2016 Modeling the Arctic freshwater system and its integration in the global system: lessons learned and future challenges J. Geophys. Res.: Biogeosci. 121 540-66

Lovenduski N S, McKinley G A, Fay A R, Lindsay K and Long M C 2016 Partitioning uncertainty in ocean carbon uptake projections: internal variability, emission scenario and model structure Global Biogeochem. Cycles 30 1276-87

Maher N et al 2019 The Max Planck Institute grand ensemble-enabling the exploration of climate system variability J. Adv. Modeling Earth Syst. 11 2050-69

Maher N, Lehner F and Marotzke J 2020 Quantifying the role of internal variability in the climate we will observe in the coming decades Environ. Res. Lett. 15054014

Marzeion B, Cogley J G, Richter K and Parkes D 2014 Attribution of global glacier mass loss to anthropogenic and natural causes Science 345 919-21

Massonnet F, Fichefet T, Goosse H, Bitz C M, Philippon-Berthier G, Holland M M and Barriat P-Y 2012 Constraining projections of summer Arctic sea ice Cryosphere 6 1383-94

Meehl G A et al 2009 Decadal prediction: can it be skillful? Bull. Am. Meteorol. Soc. 90 1467-86

Meehl G A et al 2014 Decadal climate prediction: an update from the trenches Bull. Am. Meteorol. Soc. 95 243-67

Mioduszewski J R, Vavrus S, Wang M, Holland M and Landrum L 2019 Past and future interannual variability in Arctic sea ice in coupled climate models Cryosphere 13 113-24

Niederdrenk A L and Notz D 2018 Arctic sea ice in a 1.5 C warmer world Geophys. Res. Lett. 45 1963-71

Notz D 2014 Sea-ice extent and its trend provide limited metrics of model performance Cryosphere 8 229-43

Notz D et al 2020 Arctic Sea Ice in CMIP6 Geophys. Res. Lett. 47 e2019GL086749

Notz D and Stroeve J 2016 Observed Arctic sea-ice loss directly follows anthropogenic $\mathrm{CO}_{2}$ emission Science 354 747-50

Olonscheck D and Notz D 2017 Consistently estimating internal climate variability from climate model simulations J. Clim. 30 9555-73

Perovich D K and Polashenski C 2012 Albedo evolution of seasonal Arctic sea ice Geophys. Res. Lett. 39 L08501 
Pohlmann H, Botzet M, Latif M, Roesch A, Wild M and Tschuck P 2004 Estimating the decadal predictability of a coupled AOGCM J. Clim. 17 4463-72

Rodgers K B, Lin J and Frölicher T L 2015 Emergence of multiple ocean ecosystem drivers in a large ensemble suite with an Earth system model Biogeosciences 12 3301-20

Roe G H, Christian J E and Marzeion B 2020 On the attribution of industrial-era glacier mass loss to anthropogenic climate change Cryosphere Discuss. 1-27

Rosenblum E and Eisenman I 2016 Faster Arctic sea ice retreat in CMIP5 than in CMIP3 due to volcanoes J. Clim. 29 9179-88

Rosenblum E and Eisenman I 2017 Sea ice trends in climate models only accurate in runs with biased global warming J. Clim. 30 6265-78

Schlunegger S et al 2020 Time of emergence \& large ensemble intercomparison for ocean biogeochemical trends Global Biogeochem. Cycles 34 e2019GB006453

Screen J and Deser C 2019 Pacific Ocean variability influences the time of emergence of a seasonally ice-free Arctic Ocean Geophys. Res. Lett. 46 2222-31

Senftleben D, Lauer A and Karpechko A 2020 Constraining uncertainties in CMIP5 projections of September Arctic sea ice extent with observations J. Clim. 33 1487-503

Sigmond M, Fyfe J C and Swart N C 2018 Ice-free Arctic projections under the Paris Agreement Nat. Clim. Change 8 404-8

Siler N, Proistosescu C and Po-Chedley S 2019 Natural variability has slowed the decline in western US snowpack since the 1980s Geophys. Res. Lett. 46 346-55

Smoliak B V, Wallace J M, Lin P and Fu Q 2015 Dynamical adjustment of the Northern Hemisphere surface air temperature field: methodology and application to observations J. Clim. 28 1613-29

Stroeve J, Holland M M, Meier W, Scambos T and Serreze M 2007 Arctic sea ice decline: faster than forecast Geophys. Res. Lett. 34 L0950

Stroeve J, Markus T, Boisvert L, Miller J and Barrett A 2014 Changes in Arctic melt season and implications for sea ice loss Geophys. Res. Lett. 41 1216-25
Stroeve J and Notz D 2018 Changing state of Arctic sea ice across all seasons Environ. Res. Lett. 13103001

Sun L, Alexander M and Deser C 2018 Evolution of the global coupled climate response to Arctic sea ice loss during 1990-2090 and its contribution to climate change J. Clim. $317823-43$

Swart N C, Fyfe J C, Hawkins E, Kay J E and Jahn A 2015 Influence of internal variability on Arctic sea-ice trends Nat. Clim. Change 5 86-9

Taylor K E, Stouffer R J and Meehl G A 2012 An overview of CMIP5 and the experiment design Bull. Am. Meteorol. Soc. 93 485-98

Topál D, Ding Q, Mitchell J, Baxter I, Herein M, Haszpra T, Luo R and Li Q 2020 An internal atmospheric process determining summertime Arctic sea ice melting in the next three decades: lessons learned from five large ensembles and multiple CMIP5 climate simulations J. Clim. 33 7431-54

Wallace J M, Fu Q, Smoliak B V, Lin P and Johanson C M 2012 Simulated versus observed patterns of warming over the extratropical Northern Hemisphere continents during the cold season Proc. Natl Acad. Sci. 109 14337-42

Walsh J E, Fetterer F, Scott Stewart J and Chapman W L 2017 A database for depicting Arctic sea ice variations back to 1850 Geogr. Rev. 107 89-107

Wang M and Overland J E 2009 A sea ice free summer Arctic within 30 years? Geophys. Res. Lett. 36 L07502

Winton M 2011 Do climate models underestimate the sensitivity of Northern Hemisphere sea ice cover? J. Clim. 24 3924-34

Yang C-Y, Liu J, Hu Y, Horton R M, Chen L and Cheng X 2016 Assessment of Arctic and Antarctic sea ice predictability in CMIP5 decadal hindcasts Cryosphere 10 2429-52

Yeager S G, Karspeck A R and Danabasoglu G 2015 Predicted slowdown in the rate of Atlantic sea ice loss Geophys. Res. Lett. 42 10-704

Zhang R 2015 Mechanisms for low-frequency variability of summer Arctic sea ice extent Proc. Natl Acad. Sci. $1124570-5$ 